\title{
Comparative form and function of oyster Crassostrea virginica hemocytes from Chesapeake Bay (Virginia) and Apalachicola Bay (Florida)
}

\author{
Leah M. Oliver ${ }^{1}$, William S. Fisher ${ }^{2}$ \\ ${ }^{1}$ Avanti Corporation, 1 Sabine Island Drive, Gulf Breeze, Florida 32561-5299, USA \\ ${ }^{2}$ U.S. Environmental Protection Agency, Center for Marine and Estuarine Disease Research, Gulf Breeze Environmental \\ Research Laboratory, Gulf Breeze, Florida 32561-5299, USA
}

\begin{abstract}
Oysters Crassostrea virginica from Chesapeake Bay, Virginia, and Apalachicola Bay, Florida, USA, were collected in March and October 1992 to investigate possible differences in defenserelated hemocyte activities between individuals from geographically separate populations. In March, hemolymph drawn from Chesapeake Bay oysters contained an average of $1.08 \times 10^{6}$ hemocytes $\mathrm{ml}^{-1}$ hemolymph, significantly lower than the average $1.63 \times 10^{6}$ hemocytes $\mathrm{ml}^{-1}$ hemolymph obtained from Apalachicola Bay oysters. Hemocyte number did not differ significantly in the October comparison. At both times of year, Chesapeake Bay oyster hemolymph samples contained significantly greater proportions of granular hemocytes compared to Apalachicola Bay hemolymph samples. Hemocyte samples from Chesapeake Bay oysters demonstrated a higher percentage of mobile hemocytes and greater particle binding ability than Apalachicola Bay oyster hemocytes when tested in March, but the reverse was found in the October experiments. Chesapeake Bay oyster hemocytes produced significantly more superoxide anion as measured by nitroblue tetrazolium reduction than did Apalachicola Bay oyster hemocytes in both March and October. Oyster hemolymph levels of the protozoan parasite Perkinsus marinus did not differ signifıcantly between the 2 sites at either time of year. These results demonstrate the importance of background studies to characterize site-specific differences in oyster hemocyte defense-related functions.
\end{abstract}

KEY WORDS: Invertebrate immunology $\cdot$ Crassostrea virginica $\cdot$ Hemocytes $\cdot$ Phagocytosis

\section{INTRODUCTION}

Phagocytosis and intracellular digestion by hemocytes is considered the primary defense mechanism of bivalve mollusks (Cheng 1975). Quantitative tests that measure defense-related hemocyte functions are currently used to investigate host-parasite interactions, potential immunomodulation from xenobiotic chemical exposure, and environmental influence on hemocyte defense capacity (Cheng 1988, Fisher \& Tamplin 1988, Chu \& LaPeyre 1989, Larson et al. 1989, Adema et al. 1991, McCormick-Ray \& Howard 1991, Anderson et al. 1992b, c, 1994). Research employing immunological assays has been conducted on the eastern oyster Crassostrea virginica from various locations ranging from the Gulf of Mexico to Delaware Bay, USA. Despite high inherent variability between responses of individ- ual oysters originating from a common site, deviation from a control group is often statistically demonstrable in laboratory experiments. Such findings can provide valuable information regarding potential effects of a particular chemical or disease organism, but extension of laboratory results to predict field effects may require an understanding of defense response levels from oysters in different habitats, geographic regions, and times of year.

Seasonal temperature cycles are unique to geographically distinct sites and drive gametogenesis, causing extreme changes in oyster metabolism, physiology and probably defense-related functions. Feng \& Canzonier (1970) reported relatively low summer lysozyme levels in oysters collected from the Navesink River, New Jersey, USA, as compared to winter values. Lower levels of serum lysozyme were also found in 
Chesapeake Bay, USA, oysters in summer months as compared to winter (Chu \& LaPeyre 1989) Reduced serum lysozyme was also demonstrated in oysters held in the laboratory at 20 to $25^{\circ} \mathrm{C}$ as compared to those held at 10 to $15^{\circ} \mathrm{C}$ (Chu \& LaPeyre 1993b).

Temperature effects on hemocyte function, number and morphology have been documented. Latex bead binding and locomotion activity were greater by hemocytes of oysters (collected from oceanic and estuarine habitats in Chesapeake Bay) which were maintained and tested in vitro at $22^{\circ} \mathrm{C}$ as compared to those kept at $30^{\circ} \mathrm{C}$ (Fisher \& Tamplin 1988). McCormick-Ray \& Howard (1991) sampled oysters from the Rappahannock River (Chesapeake Bay, VA) and analyzed the proportions of different hemocyte types. Changes in hemocyte subpopulations were found between January and May, with fewer granular hemocytes and more agranular cell types as temperature increased in the May samples. Such a shift could increase susceptibility to disease, since granulocytes are thought to be the main effectors in the oyster cellular defense response (Foley \& Cheng 1975. Renwrantz et al. 1979). In contrast, Chu \& LaPeyre (1993b) reported higher percent granulocytes as well as increased total hemocyte counts in hemolymph samples drawn from oysters held in the laboratory at $25^{\circ} \mathrm{C}$ as compared to $10^{\circ} \mathrm{C}$.

Available literature addressing possible differences in defense functions between geographically separate oyster populations is sparse. Cheng et al. (1993) found differences between hemocytes of Apalachicola Bay (Florida, USA) oysters and Galveston Bay (Texas, USA) oysters. Agglutination titers to specific lectins and concentrations of sugars that inhibited hemocyte clumping varied between the 2 oyster populations. Chu \& LaPeyre (1993a) studied 3 populations of Chesapeake Bay oysters and reported that oysters collected from the James River (10 ppt salinity) had higher levels of serum protein and Iysozyme, a greater percentage of granulocytes, and lower prevalence and intensity of Perkinsus marinus infections as compared with oysters collected from Wachapreague (32 ppt salinity) or Mobjack Bay (20 ppt salinity). The time required for hemocytes to spread to an ameboid shape on glass slides and their subsequent rate of locomotion differed between oysters from. Tred Avon River, an estuarine habitat, and Wachapreague, an oceanic habitat (Fisher \& Tamplin 1988). Hemocytes from estuarine oysters spread faster than hemocytes from oceanic oysters, and better maintained this function when subjected to acute salinity increase. Santarem et al. (1992) described both site-specific and seasonal differences in average circulating hemocyte number in mussels Mytilus galloprovincialis Lmk. collected in northwestern Spain.
These examples of site-related differences in oyster hemocyte morphology and activity indicate a need to study variability in hemocyte defense functions and morphology among different oyster populations. To address this question, total hemocyte number, percentage granulocytes, hemocyte locomotive activity, phagocytic ability, superoxide production, and hemolymph Perkinsus marinus infection level of oysters from Chesapeake Bay and Apalachicola Bay were measured at 2 different times of year.

\section{MATERIALS AND METHODS}

For the March 1992 experiments, oysters were collected from the Rappahannock River, a subestuary of the Chesapeake Bay (CpB) system and maintained at Virginia Institute of Marine Science (VIMS) in a flowthrough sea water system under ambicnt conditions (21 ppt, $8^{\circ} \mathrm{C}$ ) for approximately 1 mo prior to analyses. Apalachicola Bay $(\mathrm{ApB})$ oysters were collected from Cat Point Bar where ambient conditions were $10 \mathrm{ppt}$ salinity and $18^{\circ} \mathrm{C}$. Both groups of oysters $(\mathrm{n}=12$ per group) were maintained on ice during overnight transport to Gulf Breeze Environmental Research Laboratory (GB/ERL) where they were analyzed the following day.

For the October 1992 experiments, CpB oysters were collected from the James River Individuals from both the James River $(\mathrm{CpB})$ and Cat Point Bar (ApB) were removed from their natural habitat, placed on ice, and shipped to GB/ERL for processing the day following collection. Ambient conditions at the James River site and Cat Point Bar were $14 \mathrm{ppt}$ and $14^{\circ} \mathrm{C}$, and $22 \mathrm{ppt}$ and $22^{\circ} \mathrm{C}$, respectively.

On both collection dates, 12 oysters from each location were scrubbed to remove mud and fouling organisms, notched at the posterior ventral shell edge, and the mantle cavity washed copiously with $0.45 \mu \mathrm{m}$ filtered sea water (FSW) at $15 \mathrm{ppt}$. Specimens were placed notch-down in a dissecting tray to allow remaining FSW wash fluid to drain. A $3 \mathrm{ml}$ syringe fitted with a 20 gauge needle was used to withdraw 1 to $2 \mathrm{ml}$ hemolymph from the adductor muscle of each oyster. In cases where debris accidently entered the hemolymph sample or where sufficient hemolymph could not be obtained to measure all activities, a replacement oyster was selected from the same group. Oysters were processed in sets of 4, alternating between the $\mathrm{CpB}$ group and the $\mathrm{ApB}$ group.

Following withdrawal, each individual hemolymph sample was processed as follows:

(1) One drop was placed onto each of 2 methanol $(\mathrm{MeOH})$-cleaned glass slides for characterization of hemocyte morphology. 
(2) Two to three drops were placed into 1 well of a Corning 24-well culture plate (pre-loaded with $250 \mu \mathrm{l}$ FSW at iso-osmotic salinity) for measurement of hemocyte mobility.

(3) A $0.5 \mathrm{ml}$ aliquot was dispensed into an Eppendorf microcentrifuge tube to quantify Perkinsus marinus in the hemolymph.

(4) One drop was placed on each side of a hemocytometer to enumerate hemocytes and calculate density.

(5) All remaining hemolymph was gently dispensed into a labelled polyethylene tube on ice to minimize aggregation, and held for measurement of particle binding and $\mathrm{O}_{2}^{-}$production by hemocytes.

Hemocyte morphology. Hemocytes from 1 or 2 drops of hemolymph were allowed to settle on $\mathrm{MeOH}$ cleaned glass slides for $20 \mathrm{~min}$ in a humid chamber. Hemocyte monolayers were fixed in $\mathrm{MeOH}$ for $2 \mathrm{~min}$, then slides were dipped in deionized water and $\mathrm{MeOH}$ before air-drying. Slides were rehydrated and stained with Giemsa stain for $20 \mathrm{~min}$. Between 200 and 250 hemocytes from each slide were examined using a Reichert compound microscope at $400 \times$ magnification. Hemocytes were classified into granulocytes (G) or agranulocytes (AG) based on the presence of blue stained cytoplasmic granules. Percentage of each cell type was calculated for each individual oyster.

Hemocyte locomotion. Sea water from the GB/ERL flow-through system was filtered with disposable $0.22 \mu \mathrm{m}$ Nalgene filter units and adjusted using deionized water to salinities approximating ambient conditions for each oyster stock. Salinity-adjusted FSW was used to prepare reagents for in vitro tests to minimize osmotic shock to the oyster hemocytes. After 2 or 3 drops of hemolymph from individual oysters were added to culture plate wells pre-loaded with $250 \mu \mathrm{l}$ FSW, the plates were maintained at $25^{\circ} \mathrm{C}$ for 30 to 45 min to allow hemocytes to settle, spread to an ameboid shape and begin locomotion. Using a Nikon inverted microscope at $400 \times$ magnification, a field was selected that contained 12 to 20 hemocytes. A transparent plastic sheet was placed over a television monitor and hemocytes were tracked for 5 min. Marked tracks of mobile hemocytes were measured, and average rate of hemocyte locomotion (RHL) was calculated as $\mu \mathrm{m} \mathrm{min} \mathrm{m}^{-1}$ for each oyster (Fisher \& Newell 1986). The percentage of mobile hemocytes was calculated for each sample.

Particle binding by hemocytes. A $10 \mathrm{mg} \mathrm{ml}^{-1}$ yeast stock (Saccharomyces cerevisiae, Sigma Chemical Company) was prepared in advance by adding $0.5 \mathrm{~g}$ of finely ground yeast to $50 \mathrm{ml}$ FSW at approximately $15 \mathrm{ppt}$. Yeast were heat-killed by boiling for $10 \mathrm{~min}$, washed twice, and frozen in $0.5 \mathrm{ml}$ aliquots. Working yeast suspension was prepared on the day of processing. A $10 \mathrm{mg} \mathrm{ml}^{-1}$ yeast aliquot was thawed and
$0.25 \mathrm{ml}$ added to $12.75 \mathrm{ml}$ FSW at the appropriate salinity for each oyster stock. One drop was placed on each side of a hemocytometer counting chamber, and the number of yeast cells $\mathrm{ml}^{-1}$ was determined.

Lab-Tek 8-chambered microscope slides were prepared as follows. Two chambers were used for each oyster hemolymph sample to test binding at [10:1] and [1:1] particle:hemocyte ratios. First, $100 \mu l$ FSW was placed in each well, then yeast was added to give approximately 300000 particles in the left and 30000 particles in the right chamber. For the [1:1] challenge, additional FSW was added so total volume was equal to that of $[10: 1]$ challenge. The chambered slide was gently rocked to evenly distribute the yeast particles.

Hemolymph (maintained on ice after withdrawal) was mixed gently to ensure homogeneity, and the volume needed to achieve 30000 hemocytes was gently pipetted into each of the 2 chambers. Slides were incubated at $27^{\circ} \mathrm{C}$ for $1 \mathrm{~h}$, dipped in FSW to remove unbound particles, fixed for 2 min in $\mathrm{MeOH}$, and dipped in deionized water and fresh $\mathrm{MeOH}$ before airdrying. Counts were performed on a Nikon inverted microscope at $400 \times$ under phase contrast. A minimum of 200 hemocytes was examined from each chamber for bound yeast particles. The particle binding index (PBI) was calculated as follows:

$\frac{\text { No. of hemocytes with bound or ingested particles }}{\text { No. of hemocytes examined }} \times 100$.

Average number of ingested particles hemocyte ${ }^{-1}$ was also determined by examining at least 50 phagocytic hemocytes (i.e. those hemocytes that bound yeast particles) challenged at the $[1: 1]$ yeast: hemocyte ratio and recording the number of yeast particles associated with each. Particle binding capacity (PBC) was calculated as follows:

\section{No. of bound or ingested particles No. of phagocytic hemocytes examined}

Nitroblue tetrazolium (NBT) reduction test. Superoxide anion generation by oyster hemocytes was quantified by reduction of NBT dye to a formazan color product. The colorimetric quantitative method described by Anderson et al. (1992a) was scaled for analysis of unchallenged and yeast-challenged $\mathrm{O}_{2}^{-}$production by hemocytes from individual oysters. NBT $(0.05 \%$, Grade III, Sigma) was prepared on the day of processing by adding $0.01 \mathrm{~g}$ to $20 \mathrm{ml}$ FSW at the appropriate salinity for each oyster stock. This was heated to just below boiling and stirred 20 min to solubilize the NBT, cooled to room temperature, and filtered with a $0.2 \mu \mathrm{m}$ syringe-tip filter. A [10 $\mathrm{mg} \mathrm{ml}^{-1}$ ] yeast (Saccharomyces cerevisiae, Sigma) suspension was prepared in advance as described above for particle binding tests. 
Prior to hemolymph collection, high-density polypropylene tubes were pre-labelled and challenge tubes loaded with $4 \mu \mathrm{l}$ of the $10 \mathrm{mg} \mathrm{ml}^{-1}$ yeast suspension. Both unchallenged and challenged hemocyte samples were run in duplicate for each oyster. A standard hemocyte number of 100000 cells was added to each tube followed by an equivalent volume of $0.05 \%$ NBT at the appropriate salinity for each oyster stock, resulting in a final concentration of $0.025 \% \mathrm{NBT}$ for all samples. Samples were incubated on a slow platform rotator for $1 \mathrm{~h}$ at $27^{\circ} \mathrm{C}$. The reaction was terminated by adding $1 \mathrm{~N} \mathrm{HCl}$ at a volume equal to hemolymph plus NBT. Samples were centrifuged at $2940 \times g$ for $10 \mathrm{~min}$ to pellet the formazan. Supernates were removed, and samples capped and frozen until extraction.

After allowing samples to thaw for $1 \mathrm{~h}$, formazan was extracted by adding $0.125 \mathrm{ml}$ pyridine. Pyridine/formazan was transferred to Wheaton glass reaction vials, which were capped and placed in a boiling water bath for $30 \mathrm{~min}$. Vials were cooled and centrifuged at $1000 \times$ $g$ for $10 \mathrm{~min}$, then supernate absorbances were measured at $515 \mathrm{~nm}$ in a Shimadzu spectrophotometer versus a pyridine-filled reference cell. Unchallenged and challenged duplicates were averaged to give final values for unchallenged and challenged $\mathrm{O}_{2}^{-}$production.

Absorbance due to residual suspended hemocyte and yeast debris not pelleted by centrifugation was noted in preliminary experiments. Separate control samples from 8 oysters were analyzed to estimate residual particulate absorbance in the absence of NBT reduction product; control samples consisted of 100000 hemocytes plus an equal volume of iso-osmotic FSW with and without $4 \mu \mathrm{l}$ of $10 \mathrm{mg} \mathrm{ml}^{-1}$ yeast suspension. Samples were incubated $1 \mathrm{~h}$, then processed as outlined above. Unchallenged and challenged means from these 8 samples were subtracted from all subsequent measurements to correct for particulate residues.

Hemolymph Perkinsus marinus diagnosis. The technique of Gauthier \& Fisher (1990) was employed with some modification to assess Perkinsus marinus occurrence in hemolymph samples. Whole hemolymph $(0.5 \mathrm{ml})$ was placed into $1.5 \mathrm{ml}$ Eppendorf microcentrifuge tubes and spun for 5 min at $2940 \times g$. Cell-free serum was removed and pellets containing hemocytes and $P$. marinus prezoosporangia were resuspended by mixing in $0.5 \mathrm{ml}$ fluid thioglycollate medium (FTM) containing $5 \mu \mathrm{l} \mathrm{ml} \mathrm{m}^{-1}$ chloromycetin, and then $50 \mu \mathrm{l}$ Mycostatin was added to each tube without mixing. Samples were incubated at room temperature in the dark for 5 to $7 \mathrm{~d}$, then centrifuged for $5 \mathrm{~min}$ at $2940 \times \mathrm{g}$. Supernate (mostly FTM) was removed with a syringe, and pellets were resuspended in $1 \mathrm{ml} 2 \mathrm{~N} \mathrm{NaOH}$ for $1 \mathrm{~h}$ to dissolve hemocyte debris (this does not destroy the $P$. marinus prezoosporangia). Supernate (mostly
$\mathrm{NaOH})$ was removed after centrifugation at $2940 \times g$ for $5 \mathrm{~min}$. Prezoosporangia were pelleted $15 \mathrm{~min}$ at $2940 \times g)$ and washed twice with deionized water, stained with $1.0 \mathrm{ml}$ filtered Lugol's working iodine $\left(0.2 \mathrm{ml}\right.$ Lugol's stock $\mathrm{ml}^{-1}$ deionized water) and $100 \mu \mathrm{l}$ aspirated onto pre-moistened $0.22 \mu \mathrm{m}$ filter paper for counting. Prezoosporangia stained dark blue were counted using a Reichert compound microscope at $100 \times$ magnification. Dilutions were made if initial counts were over 250, and whole samples were examined if initial counts were below 25. Results were standardized $\mathrm{ml}^{-1}$ oyster hemolymph.

Histology. Sections cut through the gonad, gill, mantle and digestive diverticulae were fixed in Davidson's fixative, dehydrated in ethanol, embedded in Paraplast, stained with hematoxylin and eosin, sectioned at $7 \mu \mathrm{m}$ and observed with light microscopy at $400 \times$ magnification. The reproductive stage of the oysters was noted. Digestive diverticulae and vesicular connective tissue were examined as indicators of stress and rated as 1 = normal, 2 = moderate atrophy or edema, or $3=$ heavy atrophy or edema ( $\mathrm{J}$. Winstead pers. comm.). Parasites observed in histological sections were noted. For the March CpB samples, 12 oysters separate from those tested for hemocyte function were observed for histological condition. These oysters were held under the same conditions as those used for hemocyte testing. In all other cases, histological sections were taken from the same oysters used for hemocyte tests.

Statistical analysis. Data were analyzed using SAS (SAS Institute, Cary, NC, USA). One-way analysis of variance (ANOVA) was conducted separately on the March and October data sets to relate total hemocyte number, percentage granulocytes, hemocyte locomotive, phagocytic and superoxide production activity, and Perkinsus marinus infection level to the independent variable (collection site). Due to deviation from normality, ANOVA was conducted using ranks which do not require distributional assumptions. Significance was assigned at $\alpha<0.05$ unless otherwise noted. Correlational analysis (Pearson's procedure) was performed to identify possible relationships among hemocyte morphology, activity and $P$. marinus intensity.

\section{RESULTS}

Hemocyte number and morphology. The total number of hemocytes in hemolymph samples drawn from $\mathrm{CpB}$ oysters in March was significantly lower than found in ApB oysters (Table 1a). No significant difference was found in hemocyte number in the October collection (Table 1b). Examination of fixed hemocyte monolayers revealed that at both collection times, the proportion of granular hemocytes in $\mathrm{CpB}$ oyster sam- 
Fig. 1 Crassostrea virginica. Representative hemocytes from (A) Chesapeake Bay and (B) Apalachicola Bay in March 1992. Small arrowhead indicates agranular hemocyte, large arrowhead indicates granular hemocyte. $(400 \times)$

ples significantly exceeded that in $A p B$ oyster samples (Table 1a, b; Fig. 1). In most cases, agranular hemocytes were greatly reduced in cytoplasm.

Hemocyte locomotion. The percentage of mobile hemocytes was significantly higher for CpB oyster hemocytes in March compared to ApB hemocytes, but the reverse was found in October (Table 1a, b; Fig. 2). The rate of hemocyte locomotion measured in March was significantly greater for hemocytes from $\mathrm{CpB}$ oysters as compared to $\mathrm{ApB}$ oysters. $\mathrm{CpB}$ oyster hemocytes also moved slightly faster in October compared to ApB oyster hemocytes, but the difference between site means was not statistically significant (Table 1b; Fig. 2).

Particle binding. Significantly more hemocytes from $\mathrm{CpB}$ oysters were able to bind yeast particles at both
[10:1] and [1:1] yeast:hemocyte ratios in the March experiments (Table 1a, b; Fig. 3). As with percentage mobile hemocytes, results from particle binding analyses were reversed in October, with a greater proportion of $\mathrm{ApB}$ hemocytes showing yeast binding ability. The average $\mathrm{PBC}$ was higher for $\mathrm{CpB}$ oyster hemocytes at both times of year, but only significantly so in March (Table 1a, b).

NBT reduction test $\left(\mathrm{O}_{2}^{-}\right.$production). In March and October, hemocytes from $\mathrm{CpB}$ oysters reduced significantly more NBT under both unchallenged and yeastchallenged conditions, indicating greater production of the cytotoxic $\mathrm{O}_{2}^{-}$molecule (Table 1a, b; Fig. 4).

Perkinsus marinus infections. No significant difference was found in average $P$. marinus infection inten- 
Table 1. Crassostrea virginica. Comparison of means (SE) for putative defense-related activities of oysters from Chesapeake Bay $(\mathrm{CpB})$ and Apalachicola Bay (ApB) measured in March and October 1992. RHL: rate of hemocyte locomotion; PBI: particle binding index (\% hemocytes that bound yeast): PBC: particle binding capacity (mean no. of particles phagocyte ${ }^{-1}$ ); NBT UN, NBT CH: unchallenged and yeast-challenged $\mathrm{O}_{2}$ production as measured by NBT reduction. Site means for each date significantly different at $\cdot p<0.05, \cdots p<0.01$

\begin{tabular}{|c|c|c|c|c|c|c|}
\hline \multirow{2}{*}{$\begin{array}{l}\text { Measurement } \\
(\mathrm{n}=11 \text { or } 12)\end{array}$} & \multicolumn{3}{|c|}{ (a) March 1992} & \multicolumn{3}{|c|}{ (b) October 1992} \\
\hline & $\mathrm{CpB}$ & $\mathrm{ApB}$ & p-value & $\mathrm{CpB}$ & $\mathrm{ApB}$ & $p$-value \\
\hline Hemocyte no. $\left(\times 10^{6} \mathrm{ml}^{-1}\right)$ & $1.075(0.17)$ & $1.630(0.19)$ & $\cdot \quad 0.0342$ & $1.513(0.13)$ & $1.354(0.38)$ & 0.1000 \\
\hline$\%$ Granular hemocytes & $83.1(1.93)$ & $53.7(4.60)$ & $\cdots<0.0001$ & $68.6(4.04)$ & $43.5(5.77)$ & $\cdots 0.0010$ \\
\hline$\%$ Mobile hemocytes & $86.2(4.32)$ & $46.0(6.23)$ & $\because<0.0001$ & $17.2(4.47)$ & $39.8(4.84)$ & $\cdots 0.0030$ \\
\hline RHL & $2.92(0.17)$ & $2.20(0.24)$ & * 0.0039 & $4.13(0.71)$ & $3.82(0.32)$ & 0.7340 \\
\hline PBI, [1:1] & $43.97(1.61)$ & $31.49(1.47)$ & $\because<0.0001$ & $22.43(1.35)$ & $26.27(1.22)$ & $\cdot 0.0400$ \\
\hline PBI, [10:1] & $76.31(1.32)$ & $65.56(2.94)$ & $\because \quad 0.0062$ & $62.35\{2.80\}$ & $73.86(2.07)$ & $\because 0.0050$ \\
\hline PBC, $[1: 1]$ & $2.60(0.114)$ & $1.92(0.076)$ & $\cdots<0.0001$ & $1.89(0.092)$ & $1.68(0.046)$ & 0.0770 \\
\hline NBT UN & $0.106(0.0118)$ & $0.036(0.0049)$ & $\because<0.0001$ & $0.083(0.0136)$ & $0.045(0.0036)$ & $\cdots 0.0004$ \\
\hline $\mathrm{NBT} \mathrm{CH}$ & $0.113(0.0145)$ & $0.056(0.0112)$ & $\because \quad 0.0044$ & $0.105(0.0124)$ & $0.061(0.0059)$ & $\cdots 0.0003$ \\
\hline $\log _{10}$ Perkinsus marinus $\mathrm{ml}^{-1}$ & $2.03(0.15)$ & $2.25(0.11)$ & 0.2821 & $2.70(0.29)$ & $3.14(0.27)$ & 0.3680 \\
\hline
\end{tabular}

sity as measured by hemolymph diagnosis between $\mathrm{CpB}$ and $\mathrm{ApB}$ oysters measured in March or October (Table 1a, b). Average infection intensity was higher in October compared to March for both sites.
Histological observations. No discernible gametes were found in any of the $\mathrm{CpB}$ oysters observed in March. All ApB oysters except one had distinctly differentiated gonadal tissue ranging from $1 / 3$ to $1 / 2$ full
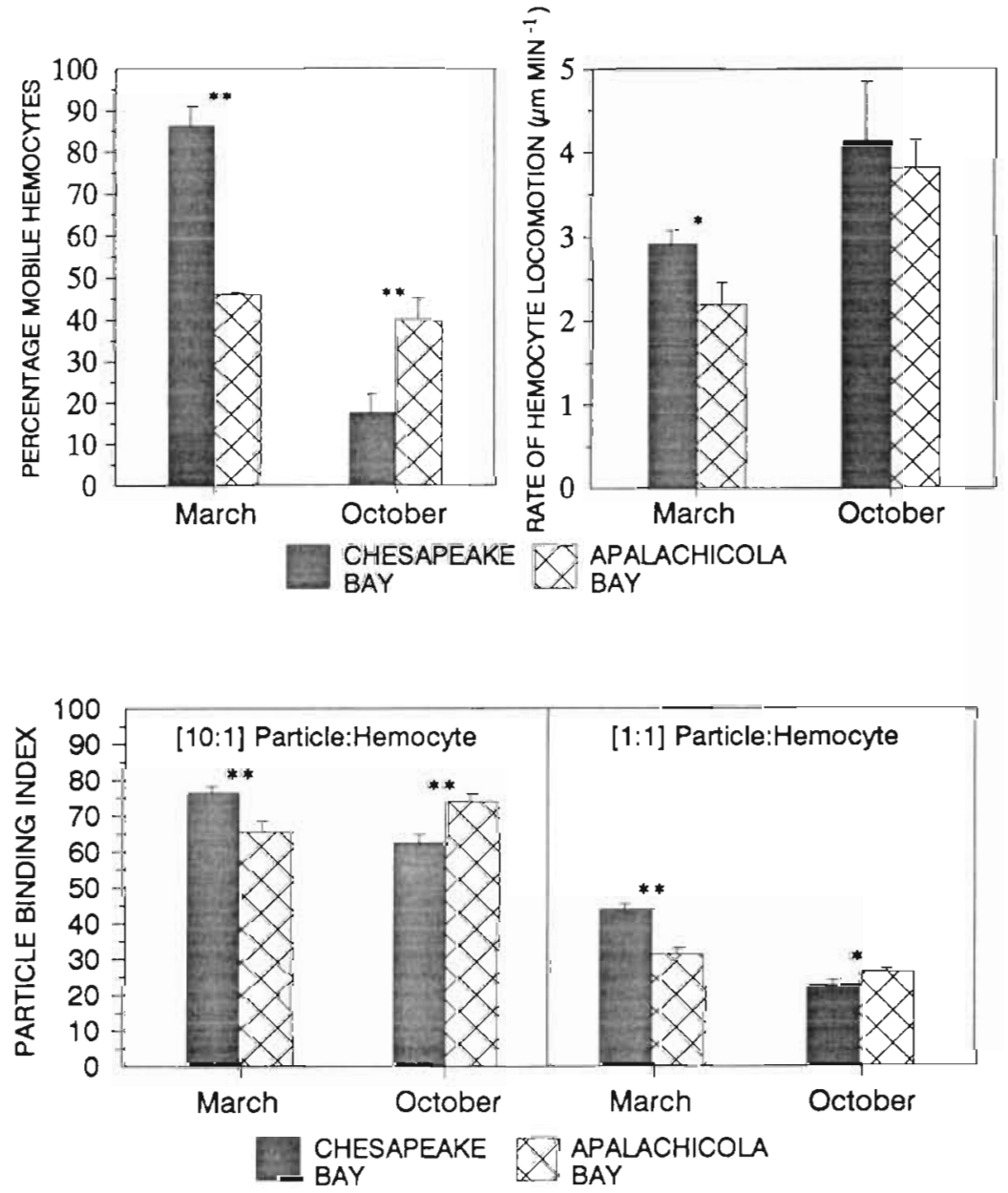

Fig. 2. Crassostrea virginica. Percentage mobile hemocytes and rate of hemocyte locomotion for oyster hemocytes from Chesapeake Bay and Apalachicola Bay in March and October 1992. Bars indicate standard errors, $n=12$ per site. Site means significantly different at $p<0.05$,

$$
\cdots p<0.01
$$

Fig. 3. Crassostrea virginica. Particle binding index ( $\%$ hemocytes that bound yeast particles) measured at $[10: 1]$ and [1:1] yeast:hemocyte ratios. Bars indicate standard errors, $n=12$ per site. Site means significantly different at $p<0.05$, $\because p<0.01$ 
Fig. 4. Crassostrea virginica. NBT reduction activity (indicative of $\mathrm{O}_{2}^{-}$production) by oyster hemocytes from Chesapeake Bay and Apalachicola Bay measured in March and October 1992. Bars indicate standard errors, $n=12$ per site. Site means significantly different at $\cdot p<0.05$, $\cdots p<0.01$

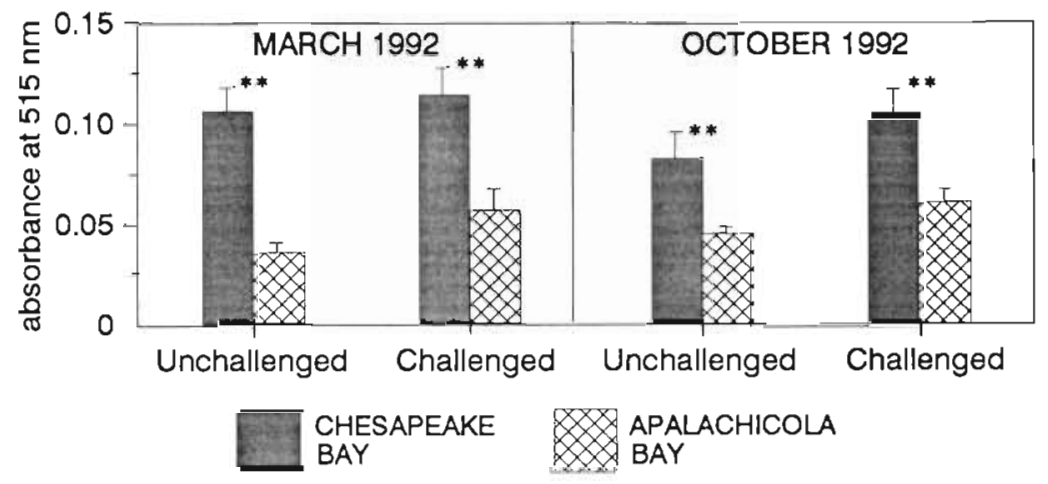

and percent mobile hemocytes, particle binding index at [1:1], particle binding capacity at [1:1], and NBT reducing activity (Table 2 ). These relationships were not reproduced when hemocyte activity tests were conducted in October; in fact negative correlations were seen between percent granulocytes and percent mobility, and between percent granulocytes and particle binding indices at [10:1] and [1:1] yeast:hemocyte ratios. Positive correlations between percent granulocytes and NBT reduction activity were seen at both times of year, and the combined data from both dates showed a highly significant positive relationship (Table 2).

\section{DISCUSSION}

Subjective observations of $\mathrm{CpB}$ and $\mathrm{ApB}$ oyster hemocytes led to this comparison of hemocyte morphology and activity. Several measurements of hemocyte activity were performed in March on oysters collected from $\mathrm{ApB}$ and oysters collected from $\mathrm{CpB}$ and maintained in flow-through ambient sea water at VIMS. Differences, as described here, were sufficient to initiate a second interbay comparison in October. Despite the small sample size, differences in hemocyte activity attributable to collection site were significant. Although causal factors for these differences cannot be identified, environmental factors have been linked with defense actitivies of oysters.

It has been proposed that warmer temperatures, such as those experienced in $\mathrm{ApB}$, can elevate the number of circulating hemocytes in oyster hemolymph by increasing the rate and pumping force of the heart (Feng 1965). This could account for the difference in circulating hemocyte number in March, since CpB oysters originated from $8^{\circ} \mathrm{C}$ and $\mathrm{ApB}$ oysters from $21^{\circ} \mathrm{C}$. However, October experiments showed a higher number of circulating hemocytes $(\mathrm{p}=0.10)$ in $\mathrm{CpB}$ oysters which originated at $14^{\circ} \mathrm{C}$, whereas $\mathrm{ApB}$ oysters were in $22^{\circ} \mathrm{C}$ water prior to collection. Neither phagocytic index nor phagocytic capacity differences described 
here can be explained based on ambient temperature alone. Chu \& LaPeyre (1993b) reported enhanced phagocytosis by hemocytes of oysters held (and tested in vitro) at $20^{\circ} \mathrm{C}$ as compared to $10^{\circ} \mathrm{C}$, with reduced activity at $25^{\circ} \mathrm{C}$. Though $\mathrm{ApB}$ oysters were in $18^{\circ} \mathrm{C}$ seawater in March compared to $8^{\circ} \mathrm{C}$ for $\mathrm{CpB}$ oysters, both the PBI and PBC were significantly higher for $\mathrm{CpB}$ oyster hemocytes at that time.

Histological observations made on tissue sections showed prominent differences in the reproductive stage of oysters from $\mathrm{CpB}$ and $\mathrm{ApB}$ in March. As expected given the contrast in ambient temperature, $\mathrm{CpB}$ oysters were not developing gametes while $\mathrm{ApB}$ oysters had sexually differentiated gonadal tissue. Oysters from both $\mathrm{CpB}$ and $\mathrm{ApB}$ had completed spawning in October, but $\mathrm{CpB}$ oysters were further advanced in gamete resorption. Differences in development of gonadal tissue may affect the number or function of circulating hemocytes involved in nutrient transport and resorption processes.

Short-term changes in environmental conditions, particularly in estuaries where daily tidal fluctuations occur, are likely to influence hemocyte function. An acute salinity increase can lengthen the time required for hemocyte spreading and decrease the rate of hemocyte locomotion, whereas a salinity decrease may enhance hemocyte activities (Fisher \& Newell 1986, Fisher \& Tamplin 1988). Fisher \& Newell (1986) found fewer granular hemocytes in oysters from high salinities (Wachapeague) compared to oysters from low salinities (Tred-Avon River). Salinity measurements in the current study at $\mathrm{CpB}$ and $\mathrm{ApB}$ were 21 and $10 \mathrm{ppt}$ in March, and 14 and $22 \mathrm{ppt}$ in October. Neither \% granulocytes nor rate of hemocyte locomotion differences found in our study can be solely attributed to ambient salinity. However, changes in salinity can affect food availability and composition. As an example, clams that were starved for $1 \mathrm{wk}$ had reduced hemocyte density compared to fed controls (Oubella et al. 1993)

Heavy Perkinsus marinus infections may be associated with increased reactive oxygen intermediate production and increased circulating hemocyte numbers in Crassostrea virginica from $\mathrm{CpB}$, according to Anderson et al. (1992C). In this study only light to medium infections were detected in oysters from both sites, and no correlation was found between $P$. marinus infection intensity and hemocyte $\mathrm{O}_{2}^{-}$production. Consequently, it did not appear to be a factor in the differences observed between oyster stocks.

Oysters from $\mathrm{CpB}$ and $\mathrm{ApB}$ experience varying disease and parasite burdens, as indicated by histological examination. Nematopsis sp. and Tylocephalum sp. were more prevalent in $\mathrm{ApB}$ oysters than $\mathrm{CpB}$ oysters in both March and October. Exposure to metazoan par- asites and bacteria has been shown to affect lysozyme levels in. oyster serum (Feng \& Canzonier 1970, Cheng 1978). In 2 other bivalve species, Sunetta scripta and Villorita cyprinoides var. cochinensis, an increase in hemocyte number was demonstrated following experimental injection of Vibrio alginolyticus into the foot (Suresh \& Mohandas 1990). Oubella et al. (1993) reported increased hemocyte density in the clams Ruditapes philippinarum and $R$. decussatus induced by pallial exposure to Vibrio P1. If similar processes are at work in the natural environment, warmer water and increased microbial burden in March may have contributed to the higher number of circulating hemocytes in ApB oysters.

Percentage granulocytes and NBT reducing activity were higher for $\mathrm{CpB}$ oyster hemocytes as compared to ApB oyster hemocytes in March and October. Correlational analysis showed positive associations between $\%$ granulocytes and NBT reduction in both March and October, while correlations between \% granulocytes and \% mobility, and \% granulocytes and particle binding, were positive in March and negative in October. These results indicate that the association of granularity with phagocytosis and locomotion may not exist year-round (Foley \& Cheng 1975, Renwrantz et al. 1979). The intuitive association between NBT reduction activity and granularity is perhaps the most plausible because granules contain enzymes that produce cytotoxic molecules, including $\mathrm{O}_{2}$, that effect intracellular killing and digestion of phagocytosed material (Badwey \& Karnovsky 1980, Auffret 1988). Phagocytosis can occur without intracellular digestion of engulfed matter as is seen in the human condition of chronic granulomatous disease (CGD), so presence of granules may not automatically confer greater phagocytic ability (Baehner \& Nathan 1968). Conclusions regarding phagocytic vitality of oysters from different sites must be carefully approached if \% granulocytes is used as an indicator of phagocytosis

The implications for the site-specific variation in oyster hemocyte function described here are far-reaching in the fields of bivalve immunotoxicology and pathobiology. Misleading conclusions could result from assuming that any presumptive indicator of hemocyte phagocytic capacity is constant year-round or between oysters from different sites. Site-specific and seasonal differences in hemocyte morphology and function must be considered if changes due to chemical contaminants or disease organisms are to be accurately determined. Should applications for quantitative hemocyte tests continue to broaden, monitoring studies to characterize site-related differences and seasonal variation will become essential components of the growing body of information regarding oyster cellular defense processes. 
Acknowledgements. We gratefully acknowledge the expertise of James Winstead who evaluated the histology slides Excellent technical assistance was provided by Ms Patrice Edwards who conducted Perkinsus marinus diagnoses and hemocyte locomotion analyses. Oysters from Chesapeake Bay were graciously donated by Dr F.-l. E. Chu. Mention of commercial products or companies does not constitute endorsement or recommendation for use by the U.S. Environmental Protection Agency. This is Gulf Breeze Environmental Laboratory contribution 855

\section{LITERATURE CITED}

Adema CM, van der Knaap WPW. Sminia T (1991) Molluscan hemocyte-mediated cytotoxicity: the role of reactive oxygen intermediates. Rev aquat Sci 4(2-3):201-223

Anderson RS, Mora LM, Thomson SA (1994) Modulation of oyster (Crassostrea virginica) hemocyte immune function by copper, as measured by luminol-enhanced chemiluminescence. Comp Biochem Physiol 108C(2):215-220

Anderson RS, Oliver LM, Brubacher LL (1992a) Superoxide anion generation by Crassostrea virginica hemocytes as measured by nitroblue tetrazolium reduction. J Invertebr Pathol 59(3):303-307

Anderson RS, Oliver LM, Jacobs D (1992b) Immunotoxicity of cadmium for the eastern oyster (Crassostrea virginica) [Gmelin, 1791]: effects on hemocyte chemiluminescence. J Shellfish Res 11(1):31-35

Anderson RS, Paynter KT, Burreson EM (1992C) Increased reactive oxygen intermediate production by hemocytes withdrawn from Crassostrea virginica infected with Perkinsus marinus. Biol Bull 183:476-481

Auffret M (1988) Bivalve hemocyte morphology. Am Fish Soc Spec Publ 18:169-177

Badwey JA, Karnovsky ML (1980) Active oxygen species and the functions of phagocytic leucocytes. A Rev Biochem 49: $695-726$

Baehner RL, Nathan DG (1968) Quantitative nitroblue tetrazolium test in chronic granulomatous disease. New Eng $\mathrm{J}$ Med 278:971-976

Cheng TC (1975) Functional morphology and biochemistry of molluscan phagocytes. Annls NY Acad Sci 266:343-379

Cheng TC (1978) The role of lysosomal hydrolases in molluscan cellular response to immunologic challenge. Comp Pathobiol 4:59-71

Cheng TC (1988) In vivo effects of heavy metals on cellular defense mechanisms of Crassostrea virginica: total and differential cell counts. J Invertebr Pathol 51:207-214

Cheng TC, Dougherty WJ, Burrell VG Jr (1993) Lectin-binding differences on hemocytes of two geographic strains of the American oyster, Crassostrea virginica. Trans Am Microsc Soc 112(2): 151-157

Chu FL-E, LaPeyre JF (1989) Effects of environmental factors and parasitism on hemolymph lysozyme and protein of

Responsible Subject Editor: A. K. Sparks, Seattle, Washington, USA
American oysters (Crassostrea virginica). J Invertebr Pathol 54:233-241

Chu FLE, LaPeyre JF (1993a) Development of disease caused by the parasite, Perkinsus marinus and defense-related hemolymph factors in three populations of oysters from the Chesapeake Bay, USA. J Shellfish Res 12(1):21-27

Chu FLE, LaPeyre JF (1993b) Perkinsus marinus susceptibility and defense-related activities in eastern oysters Crassostrea virginica: temperature effects. Dis aquat Org 16 : $223-234$

Feng SY (1965) Heart rate and leucocyte circulation in Crassostrea virginica (Gmelin). Biol Bull 128:198-210

Feng SY, Canzonier WJ (1970) Humoral responses in the American oyster (Crassostrea virginica) infected with Bucephalus species and Minchinia nelsoni. In: Snieszko SF (ed) A symposium on diseases of fishes and shellfishes. Am Fish Soc Spec Publ, Washington, DC, p 497-510

Fisher WS, Newell RIE (1986) Salinity effects on the activity of granular hemocytes of American oysters, Crassostrea virginica. Biol Bull 170:122-134

Fisher WS, Tamplin M (1988) Environmental influence on activities and foreign-particle binding by hemocytes of American oysters, Crassostrea virginica. Can J Fish Aquat Sci 45:1309-1315

Foley DA, Cheng TC (1975) A quantitative study of phagocytosis by hemolymph cells of the pelecypods Crassostrea virginica and Mercenaria mercenaria. J Invertebr Pathol 25:189-197

Gauthier JD, Fisher WS (1990) Hemolymph assay for diagnosis of Perkinsus maninus in oysters Crassostrea virginica (Gmelin, 1791). J Shellfish Res 9(2):367-371

Larson KB, Roberson BS, Hetrick FM (1989) The effects of environmental pollutants on the chemiluminescence of hemocytes from the American oyster Crassostrea virginica. Dis aquat Org 6:131-136

McCormick-Ray MG, Howard T (1991) Morphology and mobility of oyster hemocytes: evidence for seasonal variations. J Invertebr Pathol 58:219-230

Oubella R, Maes P, Paillard C, Auffret M (1993) Experimentally induced variation in hemocyte density for Ruditapes philippinarum and $R$ decussatus (Mollusca, Bivalvia). Dis aquat Org 15:193-197

Renwrantz L, Yoshino T, Cheng T, Auld K (1979) Size determination of hemocytes from the American oyster, Cras. sostrea virginica, and description of a phagocytosis mechanism. Zool Jahrb Physiol 83:1-12

Santarem MM, Figueras AJ, Robledo JAF, Caldas JR (1992) Variation of the defence mechanisms in two groups of mussels, Mytilus galloprovincialis Lmk. Seasonal and environmental effects-preliminary results. Aquaculture 107:185-188

Suresh K, Mohandas A (1990) Number and types of hemocytes in Sunetta scripta and Villorita cyprinoides var cochinensis (Bivalvia), and leukocytosis subsequent to bacterial challenge. J Invertebr Pathol 55:312-318

Manuscript first received: November 10, 1994

Revised version accepted: March 16, 1995 